\title{
Educação ambiental e representações sociais de professoras municipais
}

\author{
Angela Link Saccol ${ }^{1}$
}

angelalinksaccol@yahoo.com.br

\author{
Edival Sebastião Teixeira ${ }^{2}$ \\ edival@utfpr.edu.br
}

\section{Resumo}

$\mathrm{O}$ artigo apresenta resultados de pesquisa que objetivou identificar e analisar as representações sociais de educação ambiental de professores dos anos iniciais do ensino fundamental de escolas municipais de Pato Branco, no Paraná. Participaram do estudo seis docentes de uma escola urbana e seis de uma escola rural. Os dados foram coletados mediante entrevista, aplicação da técnica de hierarquização de evocações e análise de documentos com base na análise de conteúdo. Os resultados indicam que as representações sociais de educação ambiental dos participantes da pesquisa consistem em um conjunto de procedimentos cuja finalidade é desenvolver a consciência dos educandos para o respeito e a preservação do ambiente.

Palavras-chave: educação ambiental, representações sociais, ensino fundamental.

\section{Introdução}

A teoria das representações sociais inicia com Serge Moscovici na década de 1950. Mas foi em 1961, com o lançamento do livro Representação Social de Psicanálise, que a teoria começa a ser difundida. Nesse trabalho, o autor apresenta os resultados de um estudo realizado na França, a partir de questionários e matérias de jornais, sobre as

1 Mestre em Desenvolviemnto Regional pela Universidade Tecnológica Federal do Paraná - UTFPR.

2 Doutor em Educação pela Universidade de São Paulo. Professor da UTFPR. 
representações existentes sobre a psicanálise. Ele buscava compreender como o saber científico se fixava na consciência das pessoas.

Na visão de Farr (2010, p. 45), Moscovici “estava interessado em observar o que acontece quando um novo corpo de conhecimento, como a psicanálise, se espalha dentro de uma população humana" e não propriamente discutir a teoria psicanalítica. Ao tentar entender como um sujeito leigo se apropriava de um saber científico, Moscovici estava estudando, de fato, o senso comum.

Outra caracterização das representações sociais é apresentada por Jodelet (2001, p. 22) da seguinte maneira:

[...] é uma forma de conhecimento, socialmente elaborada e partilhada, com um objetivo prático, e que contribui para a construção de uma realidade comum a um grupo social. Igualmente designada como saber do senso comum ou ainda como saber ingênuo, natural, esta forma de conhecimento é diferenciada, entre outras, do conhecimento científico. Entretanto, é tida como um objeto de estudo tão legítimo quanto este, devido à sua importância na sua vida social e à elucidação possibilitadora dos processos cognitivos e das interações sociais.

As representações sociais, portanto, referem-se a conhecimentos do senso comum, embora nem todo conhecimento possa ser considerado representação social, pois somente aqueles que fazem parte da vida cotidiana das pessoas, que são elaborados socialmente e que trabalham no sentido de interpretar, pensar e agir sobre a realidade, é que assim podem ser considerados. Assim, trata-se, como destacam Santos e Almeida (2005), de um conhecimento prático que se opõe ao pensamento científico, embora dele seja derivado.

A teoria tem como pressuposto que os sujeitos buscam explicações e teorizam sobre uma série infinita de assuntos e procura explicar como esse fenômeno humano se manifesta a partir de uma perspectiva coletiva, sem, contudo, subtrair ao sujeito sua singularidade. (MOSCOVICI, 2004)

O estudo das representações sociais investiga, então, como se formam e como funcionam os sistemas de referência que utilizamos para 
classificar assuntos, pessoas e grupos e para interpretar os acontecimentos da realidade cotidiana. Por isso, tais investigações aportam elementos essenciais para a compreensão de comportamentos e práticas sociais.

Após as contribuições iniciais de Moscovici, muitos outros pesquisadores desenvolveram importantes colaborações à teoria e, atualmente, ela vem sendo muito utilizada nas áreas de psicologia, educação, saúde, meio ambiente, entre outras para explicar comportamentos humanos em diversos contextos como, por exemplo, os estudos de Sousa e Villas Bôas (2011), que retratam os desafios da teoria das representações sociais nos estudantes de educação e licenciatura sobre o trabalho docente; a pesquisa de Aléssio e Santos (2005) sobre a representação social de violência num contexto rural e, ainda, Sato (2004), que realizou um estudo sobre a representação social do trabalho penoso.

A teoria das representações sociais também tem sido bastante utilizada para compreender o modo como professores de diversos níveis concebem a educação ambiental na atualidade. Destaca-se, por exemplo, o estudo de Tristão (2008), que investigou os sentidos da educação ambiental na formação de professores diante dos desafios atuais que são colocados à educação, como a necessidade de inclusão da educação ambiental nos processos de formação de professores. Velloso (2006), por sua vez, desenvolveu sua pesquisa com o intuito de compreender a dinâmica da educação ambiental na rede pública da cidade do Rio de Janeiro, apreendendo suas concepções, problemas e desafios, através da experiência de trabalho de um grupo de professores que trabalha diretamente com a questão ambiental. Outro estudo, esse desenvolvido por Araujo (2007), analisou algumas representações sociais de educação ambiental de três professores da rede municipal de ensino de Santa Maria (RS), onde atua como professora e supervisora pedagógica dos anos finais do ensino fundamental.

Esses estudos corroboram a importância e relevância da teoria das representações sociais para a investigação de questões como as da pesquisa relatada no presente artigo. Com efeito, a teoria em questão oferece novos caminhos para a explicação de mecanismos em que os fatores sociais atuam sobre o processo educacional e seus resultados, 
tanto nos aspectos macro como microscópicos. (DOTTA, 2006)

Moreira (2001) destaca que a população tem dificuldades em entender as questões ambientais de maneira mais abrangente, uma vez que as mensagens transmitidas nos meios de comunicação incluem "Preserve..." "Conserve..." "Não jogue..." "Não destrua...", visão essa apenas de cuidado. Esse mesmo autor prossegue afirmando que "ao discutir ou definir meio ambiente é importante que consideremos as complexas relações existentes na sociedade e entre os diversos elementos da natureza e suas interdependências" (MOREIRA, 2001, p. 75). Em outras palavras, as ações devem estar vinculadas às questões socioambientais para terem resultados efetivos.

Nessa perspectiva, a compreensão do professor sobre os temas envolvendo a esfera ambiental são essenciais, já que são eles, os professores, que auxiliam na formação de novas interpretações de mundo, homem e sociedade. Penteado (2001, p. 54) comenta que:

[...] o desenvolvimento da cidadania e a formação de uma consciência ambiental têm na escola um local adequado para sua realização através de um ensino ativo e participativo, capaz de superar os impasses e insatisfações vividas de modo geral pela escola da atualidade, calcado em modos tradicionais.

Isso porque, conforme Gouvêa (2006), durante certo tempo, a educação ambiental se restringiu a cumprir seu papel numa perspectiva preservacionista, reduzindo-se a práticas esporádicas, relacionadas a datas comemorativas, miniprojetos, cuidado com plantas e reciclagem de lixo.

Esse discurso conservacionista, destacado nos anos 1970 e 1980, foi responsável direto pela compreensão equivocada de que a questão ambiental era dissociada da questão social. Só na metade da década de 1980 que, segundo Lima (2009), houve a formação de alianças entre os movimentos sociais e as entidades ambientalistas, fato esse que acabou gerando o que é conhecido como socioambientalismo.

Lima (2009, p. 151) ressalta que:

[...] o amadurecimento da experiência e do debate 
ambiental e político fez revelar, a ambientalistas e membros dos movimentos sociais, que as questões social e ambiental não eram antagônicas, mas complementares, e que a degradação que atingia a sociedade e o ambiente eram produzidas por um mesmo modelo de desenvolvimento que, em última instância, penalizava, preferencialmente, a qualidade de vida dos mais pobres.

Para cumprir esse papel, a educação ambiental necessita envolver novos desafios e reflexões, promover o contato das pessoas com seu entorno natural e social, para assim, transformar-se em uma proposta educativa crítica. Na perspectiva de Leff (2004), é necessário articular o educando ao conhecimento, no sentido de fazê-lo descobrir os sentidos do saber, desenvolver o pensamento crítico, reflexivo para combater as condutas automatizadas ainda presentes na sociedade.

Hoje, faz-se necessário pensar nas relações existentes entre os elementos da natureza e a sociedade, suas interdependências, produção, consumo, modos de vida e desigualdades, para tornar o homem mais crítico e transformador, responsável e participante do processo civilizatório, como salienta Carvalho (2008).

Assim, a introdução da educação ambiental no contexto escolar pode propiciar uma renovação, tendo em vista que se busca uma educação que contribua para o desenvolvimento integral dos sujeitos, "na intenção de contribuir para uma mudança de valores e atitudes, formando um sujeito ecológico capaz de identificar e problematizar as questões socioambientais e agir sobre elas" (CARVALHO, 2008, p. 156157, grifo do autora).

Nesse sentido, Medina e Santos (2008, p. 12) salientam que a escola necessita ficar atenta a esses novos e essenciais conhecimentos, os quais exigem respostas inovadoras e, ainda, "que permitam formar efetivamente o cidadão crítico, reflexivo e participativo, apto para a tomada de decisões, que sejam condizentes com a consolidação de democracias verdadeiras e sem exclusão da maioria de seus membros".

Concordando-se com Reigota (2007), importante e decisivo passo para o desenvolvimento de projetos de educação ambiental consiste na identificação das representações sociais das pessoas envolvidas no processo, sobretudo, educadores e educandos. Essa foi a motivação do 
estudo apresentado neste artigo, cujo objetivo foi identificar e analisar as representações sociais de educação ambiental de professores dos anos iniciais do ensino fundamental de escolas municipais de Pato Branco, no Paraná.

\section{Metodologia}

A pesquisa se desenvolveu com 12 professoras da rede municipal de ensino da cidade de Pato Branco, no Paraná, sendo uma escola rural e uma escola urbana. Nessas instituições de ensino, iniciou-se a coleta de informações através de entrevistas com as diretoras e as professoras regentes do $1^{\circ}$ ao $5^{\circ}$ ano do Ensino Fundamental. Focalizaram-se basicamente suas concepções de educação ambiental, seus processos de formação como docentes e suas práticas pedagógicas em educação ambiental. As entrevistas foram transcritas e submetidas à análise de conteúdo, com o intuito de compreender os significados/sentidos que os sujeitos dão às suas informações, conforme Bardin (1977).

A análise de conteúdo permitiu identificar 32 elementos verbais que fazem parte da representação social investigada. Esses elementos, por sua vez, foram analisados mediante a técnica descrita por Almeida (2005), denominada "triagens hierárquicas sucessivas". Essa técnica se caracteriza por apresentar duas etapas: a primeira consiste em levantar elementos da representação mediante o emprego de um instrumento de evocação livre - no caso em questão a entrevista; numa segunda etapa os elementos, então, foram escritos em cartões e apresentados aos sujeitos, solicitando-se que cada um separasse as 16 palavras que lhe pareciam as mais características do objeto da representação de educação ambiental; a seguir, eles deveriam escolher as oito palavras mais representativas e assim sucessivamente até que se chegasse "a uma única palavra que melhor representa, na perspectiva do sujeito, mais efetivamente o objeto" (ALMEIDA, 2005, p. 153).

Com a utilização dessa técnica, foram identificados elementos estruturais da representação social de educação ambiental dos sujeitos da pesquisa e, dessa forma, obtiveram-se elementos para uma análise 
mais segura acerca do objeto da investigação.

Finalmente, num terceiro procedimento, analisaram-se o plano de ensino dos professores e o Projeto Político-Pedagógico das escolas onde os sujeitos da pesquisa atuam, com o intuito de comparar as práticas pedagógicas em educação ambiental anunciadas nesses documentos com as representações sociais dos docentes.

\section{Resultados e discussão}

Em razão do sigilo aos professores e diretores, utilizaram-se trechos de falas identificados por letras e números. As letras PR designam os professores da escola rural, bem como DR a diretora da escola rural; as letras PU e DU designam respectivamente os professores e a diretora da escola urbana. Os números variam de 1 a 5 de acordo com a turma do referido professor ( 1 para o $1^{\circ}$ ano do ensino fundamental, 2 para o $2^{\circ}$ ano do ensino fundamental e assim por diante).

Através da observação dos dados que obtivemos com as entrevistas e com a técnica da hierarquização das evocações, identificamos que a representação social de educação ambiental das professoras se estrutura em torno da importância da "conscientização" para "respeitar" e "preservar" o ambiente. Trata-se, então, de que essa educação, para os sujeitos da pesquisa, consiste em um conjunto de procedimentos cuja finalidade é desenvolver a consciência para com o respeito e a preservação do ambiente. Ambiente esse, contudo, considerado apenas em seus aspectos naturais, como se pode observar nos fragmentos de entrevista exemplificados a seguir:

Conscientizar as crianças para que as coisas aconteçam; tudo o que envolve meio ambiente é importante. Quanto mais houver conscientização melhor é a qualidade de vida. [...] Como nós já trabalhamos na escola já, fomos contemplados com excelente trabalho durante o ano retrasado sobre plantas medicinais que também faz parte do nosso meio ambiente, ano passado trabalhamos sobre água por 5 ou 6 meses e a nossa escola desenvolve um trabalho muito amplo sobre isso, $\mathrm{e}$ a preservação de fontes (PR2). 
Quando se tem consciência do que é correto, se vai para uma prática também correta (PR5).

É preciso conscientização para todos; deve-se estar consciente para se ver a importância que a educação ambiental faz para as pessoas. [...] Então se o ambiente é minha casa, meu jardim. Como posso fazer pra cuidar das árvores, do caminho que eu estou... partindo muito deles e mostrando em atividades, textos, recortes, perguntas, não tirando a interpretação deles, mas tentando conscientizar do melhor, porque o ambiente vai retornar para eles, é o ambiente que eles fazem parte (PU2).

Palavra mais ampla abrange todo o contexto escolar bem como a relação entre as demais informações citadas (palavras). É a palavra-chave: não adianta ter internet, informação se o professor não for tocado na sua consciência, deve ter comprometimento (PU5).

É preciso estar consciente do que acontece para atuar com os alunos; a partir da conscientização tudo é possível. [...] Se nós professoras trabalharmos e conscientizarmos nossos alunos no dia a dia, nós vamos ter um ambiente melhor, uma conservação melhor para que em anos futuros nós tenhamos onde viver, um ar puro para respirar e água limpa para beber. Eu acho que temos que ter uma educação para transmitir aos nossos filhos, e nossos alunos também (DU).

[...] no meu entendimento para o meio ambiente ser preservado precisa sim de uma conscientização muito grande a respeito disso, do papel de chicle, do papelzinho de bala, do toco de cigarro (PR4). Vejo a educação ambiental como organização do espaço de sala de aula, o cuidado, a higiene com o local onde se está, tanto com as aparas do lápis ou o papel de recorte. Então, se a gente não trabalhar com eles desde pequenos, eles não vão crescer com essa noção de cuidar do local onde eles vivem, lógico que, a partir disso, eles vão cuidar do ambiente em que eles estão e estender aos demais ambientes (PU1).

Primeiramente começamos pela preservação do espaço em se vive, a boa convivência entre as crianças, a questão de boas maneiras, e a partir de dentro da sala ir pra fora, trabalhando a boa 
convivência fora da sala, no pátio e sempre trabalhando a questão ambiental, de preservação da água, ambiente, das matas, partindo sempre do entendimento de preservação local (PU3).

O resultado da aplicação da técnica de hierarquização corrobora o que afirmamos sobre que a representação social de educação ambiental tem a ver com o desenvolvimento da consciência para com o respeito e a preservação do ambiente.

$\mathrm{Na}$ análise das entrevistas, identificamos 32 palavras-chave, as quais foram escolhidas pela sua representatividade no conjunto das respostas das professoras. Essas palavras foram submetidas ao procedimento de hierarquização, para cada professora em separado e, após essa etapa, resultaram como centrais na representação as palavras "conscientização", "respeito" e "preservação".

Os dados que encontramos são compatíveis com os achados de Sander (2012) e Kus (2012), os quais também desenvolveram suas pesquisas na temática das representações sociais e educação ambiental.

Sander (2012), em sua pesquisa acerca das representações sociais de professores do $5^{\circ}$ ano do ensino fundamental de Pato Branco (PR), sobre meio ambiente e a relação dessas representações com a prática pedagógica em educação ambiental, evidenciou uma visão conservadora de perceber o meio ambiente, bem como seus reflexos na prática pedagógica dos sujeitos pesquisados. Após entrevista semiestruturada, técnica de evocação livre e análise documental de registros docentes, essa autora observou que há uma compreensão de foco naturalista, "conscientizar para preservar a natureza" e que as práticas pedagógicas utilizam elementos midiáticos e projetos da iniciativa privada como ferramentas, os quais se intitulam como voltados à educação ambiental e apresentaram igualmente uma concepção de preservação da natureza.

Kus (2012), por sua vez, realizou sua pesquisa em duas escolas de ensino médio da rede pública localizados em Clevelândia (PR), objetivando identificar e analisar as concepções de meio ambiente dos professores e compará-las com suas práticas pedagógicas em educação ambiental. Através das entrevistas e da técnica de evocação livre, o autor constatou a importância atribuída à preservação dos recursos naturais, 
com destaque para a água e a degradação ambiental. No que diz respeito à concepção de educação ambiental dos sujeitos de sua pesquisa, Kus (2012) destaca que essa é concebida e executada como um conjunto de práticas educativas voltadas ao desenvolvimento de atitudes para a preservação do meio.

Retornando às docentes das escolas urbana e rural pesquisadas, nossos dados evidenciam que há coerência entre o que elas entendem por educação ambiental e o modo como concebem e executam suas práticas nessa temática.

Da mesma forma, observa-se que a representação social de educação ambiental dessas professoras é compatível com as normativas brasileiras para a educação ambiental. Com efeito, no próprio documento elaborado pelo Ministério da Educação para nortear os rumos da escola, os Parâmetros Curriculares Nacionais (BRASIL, 1997), essa mesma ideia é apresentada como sendo finalidade da educação ambiental, cuja ênfase está na mudança de comportamentos visando à preservação da natureza. Esse documento destaca que:

[...] a principal função do trabalho com o tema Meio Ambiente é contribuir para a formação de cidadãos conscientes, aptos para decidirem e atuarem na realidade socioambiental de um modo comprometido com a vida, com o bem-estar de cada um e da sociedade, local e global. Para isso é necessário que, mais do que informações e conceitos, a escola se proponha a trabalhar com atitudes, com formação de valores, com o ensino e a aprendizagem de habilidades e procedimentos. E esse é um grande desafio para a educação. Comportamentos "ambientalmente corretos" serão aprendidos na prática do dia-a-dia na escola: gestos de solidariedade, hábitos de higiene pessoal e dos diversos ambientes, participação em pequenas negociações podem ser exemplos disso (BRASIL, 1997, p. 25).

Outro documento que também evidencia essa mesma concepção é a Lei Federal 9.795, de 27 de abril de 1999, que ressalta em seu artigo $1^{\circ}$ que:

Entende-se por educação ambiental os processos por meio dos quais o indivíduo e a coletividade 
constroem valores sociais, conhecimentos, habilidades, atitudes e competências voltadas para a conservação do meio ambiente, bem de uso comum do povo, essencial à sadia qualidade de vida e sua sustentabilidade (BRASIL, 1999).

Pode-se dizer, portanto, que o modo de compreender a educação ambiental por parte da escola e das professoras pesquisadas reflete o que é manifestado nos documentos da política educacional, a qual, por sua vez, sustenta-se na perspectiva hegemônica (conservadora) da educação ambiental, enfatizando apenas mudanças de comportamentos para preservar o meio ambiente. (LIMA, 2009;LOUREIRO, 2005)

Por isso, justamente pela coerência entre a representação e a normatização, não podemos deixar de notar, também, indícios da perspectiva conservadora de educação ambiental pela ênfase dada apenas à conscientização para a preservação do ambiente. Ambiente esse, diga-se, ao que parece percebido pelas professoras como sendo apenas o local onde se vive pela ênfase que deram aos aspectos naturais, em detrimento dos aspectos históricos, políticos, sociais e econômicos que não se separam da e na relação entre sociedade e natureza.

Identificamos também indícios de outra perspectiva que apontam uma visão de educação ambiental para além da escola, como exemplificado na fala das professoras a seguir:

[...] a geração posterior é a geração que vai transmitir os conhecimentos de consciência ecológica e a questão da atualidade, as formas de evitar desperdício, divulgação de metas e conhecimentos que são aplicados em sala de aula, estendendo pra família, comunidade e bairro. Agora, temos o trabalho da paz e junto com a comunidade vamos trabalhar a dengue, separação de lixo, organização de jardins, pintura do meio-fio das ruas. Tem o projeto da água que está sendo concluído hoje. Tem as estações do ano, higiene da casa do corpo... são temas anuais (PU5).

[...] a gente trabalhou diversos temas do meio ambiente, trabalhamos com a plantação, com o cultivo do chá para a saúde, trabalhamos o solo, o cuidado; e esse ano que passou nós trabalhamos 
sobre as fontes, os olhos d'água, a preservação das fontes e até fizemos um trabalho de campo fomos lá, organizamos as fontes que levam água para as pessoas, então foi assim um trabalho em conjunto com a família, um envolvimento geral da comunidade (PR4).

Verificamos que as professoras se mostraram conscientes acerca da problemática ambiental e da importância de educar para hábitos mais corretos. Segundo Trevisol (2004), essa sensibilidade ecológica já é o início de uma condição favorável para qualquer atividade de educação ambiental. E, apesar da presença de uma concepção de meio ambiente como natureza, há a aposta em soluções mais eficazes como o diálogo e discussão sobre a realidade em que os alunos vivem.

No que se refere ao terceiro procedimento de coleta de dados, a análise dos planos de ensino (cadernos) e os Projetos Políticos-Pedagógicos das escolas, foi possível observar que as professoras apresentam certa resistência nos registros sobre o que é desenvolvido em sala de aula no quesito educação ambiental.

As atividades descritas nos cadernos se referem aos quatro primeiros meses de aula deste ano e são basicamente sobre o Dia Mundial da Água, em 22 de março, em que constam leituras, poesias, acrósticos, caça-palavras e desenhos. As questões de interpretação se remetiam ao texto e poucas vezes proporcionavam uma relação com o contexto da escola ou mesmo do aluno. É importante salientar que essas atividades pontuais foram desenvolvidas durante a semana em que houve essa comemoração e depois não foi possível observar retorno a esse material ou conteúdo. Além disso, as atividades estavam referenciadas nas disciplinas de ciências, geografia, ou língua portuguesa.

Foi relatado também pelas professoras que houve um diálogo acerca do tema durante a semana, com ênfase nos cuidados e preservação da água, bem como da sua importância dentro do contexto ambiental, porém sem anotações específicas.

Apenas uma professora, PU5, tinha em seu caderno um projeto elaborado sobre o Dia Mundial da Água para a turma, com textos retirados da internet sobre a água, a Declaração Universal dos Direitos da 
Água e atividades que englobavam outras disciplinas, como informática e ensino religioso. Segundo essa mesma professora, esse projeto era para todas as turmas da escola urbana, mas nada foi constatado nem mencionado pelas demais professoras e diretora. Em três professoras, nada foi encontrado nos cadernos sobre educação ambiental.

Analisando-se as atividades desenvolvidas e descritas nos Projetos Políticos-Pedagógicos das escolas, foi possível perceber que a questão do meio ambiente ainda está intimamente ligada com as disciplinas de ciências e geografia. Além disso, reafirmando o que dissemos acerca da representação social de educação ambiental, os documentos são explícitos quanto ao modo como concebem a finalidade da educação em geral:

Proporcionar situações de convivência harmônica com respeito mútuo, solidariedade e justiça em todos os níveis do ambiente social e escolar (PATO BRANCO, 2008, p. 11).

Significar os conteúdos curriculares como meios para constituição de competências e valores necessários à formação de cidadãos conscientes e críticos capazes de articular a transformação da realidade em que vivem num ambiente digno e de qualidade tanto social quanto econômica (PATO BRANCO, 2008, p. 19).

Assim, é preciso planejar oportunidades em que as crianças dirijam suas próprias ações, tendo em vista seus recursos individuais e os limites inerentes ao ambiente (PATO BRANCO, 2008, p. 33).

Ofertar um ambiente acolhedor, higienizado, com condições de desempenhar as atividades em plena harmonia (PATO BRANCO, 2011, p. 16).

Buscamos em Nóvoa (1999, p. 13-14), um esclarecimento acerca dessa carência das práticas construídas por parte dos professores, pois esse autor aponta que há uma abundância de discursos sobre o papel que os professores são incumbidos a desempenhar na construção da chamada "sociedade do futuro" e que em sempre correspondem à realidade. E destaca que:

O excesso dos discursos esconde a pobreza das práticas políticas. Neste fim de século, não se vêem surgir propostas coerentes sobre a profissão 
docente. Bem pelo contrário. As ambigüidades são permanentes. Por um lado, os professores são olhados com desconfiança, acusados de serem profissionais medíocres e de terem uma formação deficiente; por outro lado, são bombardeados com uma retórica cada vez mais abundante que os considera elementos essenciais para a melhoria da qualidade do ensino e para o progresso social e cultural.

Esse excesso de discursos nos faz voltar ao final do século XIX, quando os professores eram revestidos de poderes e havia um consenso social em torno da missão do professor. Hoje percebemos que o contexto é um pouco diferente.

Queremos dizer, dessa forma, e parafraseando Nóvoa (1999), que esse exagero de discursos leva, por vezes, à pobreza de políticas educativas realmente efetivas, à pobreza dos programas de formação de professores, à pobreza de práticas pedagógicas e à pobreza das práticas associativas docentes. Por sua vez, essa falta ou escassez aparece refletida na sala de aula e nos pensamentos dos professores, por exemplo, através de atividades pontuais referentes a certa data comemorativa e que não se retornam a esse conteúdo mais tarde, pelo menos no papel. Isso não significa de maneira alguma, como destacado anteriormente, transferir ao professor e à sua formação a responsabilidade pelo atual desempenho da rede pública de ensino, mas a todo o conjunto de fatores os quais chegam a essa análise, até porque, as professoras entrevistadas não tiveram formação na questão ambiental e mesmo assim desenvolvem seus trabalhos da melhor maneira que podem.

Essas práticas pedagógicas repercutem, em certo sentido, os processos de formação das professoras em educação ambiental. Com efeito, dentre as 12 professoras pesquisadas, apenas uma referiu ter tido em sua graduação uma disciplina específica que tratou da problemática ambiental. As demais mencionaram que essa temática foi vista de modo muito superficial em seus cursos. 


\section{Considerações finais}

Na análise dos Projetos Políticos-Pedagógicos das escolas bem como o caderno das professoras, observamos a inexistência quase que total de registros das atividades desenvolvidas em sala de aula. Nos relatos das entrevistas e na análise documental, foram apontados que os diálogos sobre educação ambiental são realizados, porém ainda muito ligados às datas comemorativas.

Também foi constatado que as práticas pedagógicas das pesquisadas repercutem, em certo sentido, os processos de formação das professoras em educação ambiental. Reforçou-se a questão da frágil formação dessas professoras, as quais são exigidas de muitas formas e realizam o que podem para não deixar os alunos sem acesso ao conhecimento, justificando-se, então, as atividades pontuais encontradas nos materiais dessas professoras. A educação ambiental, portanto, é uma realidade para as docentes pesquisadas. Porém, a exemplo do que nos mostra Guimarães (2010), tal prática pedagógica se apresenta fragilizada em sua prática pedagógica.

E, assim, não estranha, embora cause preocupação, que nossos dados demonstrem coerência entre a representação social de educação ambiental identificada, os processos de formação das participantes da pesquisa e suas práticas pedagógicas pontuais. Isto é, uma representação conservadora que se manifesta no discurso e em práticas pontuais.

Agradecimento: Os autores agradecem ao Conselho Nacional de Desenvolvimento Científico e Tecnológico $(\mathrm{CNPq})$ pelo apoio à pesquisa. 


\section{Referências}

ALÉSSIO, Renata Lira dos Santos; SANTOS, Maria de Fátima de Souza. Desenvolvimento humano e violência na zona rural. In: SANTOS, Maria de Fátima de Souza; ALMEIDA Leda Maria de (org.). Diálogos com a teoria das representações sociais. Recife: Ed. Universitária da UFPE/Ed. Universitária da UFAL, 2005, p. 77-98.

ALMEIDA, Angela Maria de Oliveira. A pesquisa em Representações sociais: proposições metodológicas. In: SANTOS, Maria de Fátima de Souza; ALMEIDA Leda Maria de (org.). Diálogos com a teoria das representações sociais. Recife: Ed. Universitária da UFPE/Ed. Universitária da UFAL, 2005, p. 117-160.

ARAUJO, Lila Maria Malcorra. Formação docente, educação ambiental e representações sociais: uma pesquisa com três professores(as) especialistas em educação ambiental. 2007. 96 f. Dissertação (Mestrado em Educação) - Universidade Federal de Santa Maria, Santa Maria, RS, 2007.

BARDIN, Laurence. Análise de conteúdo. Lisboa: Edições 70, 1977.

BRASIL. Parâmetros Curriculares Nacionais: meio ambiente e saúde. Secretaria de Educação Fundamental. Brasília, 1997. BRASIL. Política Nacional de Educação Ambiental. Lei Federal $n^{\circ}$ 9.795 de 27 de abril de 1999.

CARVALHO, Isabel C. de M. Educação ambiental: a formação do sujeito ecológico. 4. ed. São Paulo: Cortez, 2008.

DOTTA, Leanete Teresinha Thomas. Representações sociais do ser professor. Campinas, SP: Editora Alínea, 2006.

FARR, Robert M. Representações sociais: a teoria e sua história. In: 
GUARESCHI, Pedrinho; JOVCHELOVITCH, Sandra (org.). Textos em representações sociais. 10. ed. Petrópolis: Vozes, 2010, p. 31-62.

GOUVÊA, Giana Raquel Rosa. Rumos da formação de professores para educação ambiental. Educar em Revista, Curitiba, n. 27, p. 163-179, 2006.

GUIMARÃES, Mauro. A formação de educadores ambientais. 8. ed. Campinas: Papirus, 2010.

JODELET, Denise. Representações sociais: um domínio em expansão. In: JODELET, Denise (org.). As representações sociais. Rio de Janeiro: EdUERJ, 2001, p. 17-44.

KUS, Helder Jaime. Concepções de meio ambiente de professores de educação básica e práticas pedagógicas em educação ambiental. 2012. 83 f. Dissertação (Mestrado em Desenvolvimento Regional) - Universidade Tecnológica Federal do Paraná, Pato Branco, PR, 2012.

LEFF, Enrique. Saber ambiental: sustentabilidade, racionalidade, complexidade, poder. 3. ed. Petrópolis: Vozes, 2004.

LIMA, Gustavo Ferreira da Costa. Educação ambiental crítica: do socioambientalismo às sociedades sustentáveis. Educação e Pesquisa, São Paulo, v. 35, n. 1, p. 145-163, jan./abr. 2009.

LOUREIRO, Carlos Frederico Bernardo. Complexidade e dialética: contribuições à práxis política e emancipatória em educação ambiental. Educação e Sociedade, Campinas, v. 26, n. 93, p. 1.473-1.494, set./dez. 2005.

MEDINA, Naná M.; SANTOS, Elizabeth C. Educação ambiental: uma metodologia participativa de formação. 5. ed. Petrópolis: Vozes, 2008. 
MOREIRA, Antônio C. Caminhos a serem construídos para uma sociedade sustentável. In: FONTANA, Airton (org.). Construindo a sustentabilidade: uma perspectiva para o desenvolvimento regional. São Miguel do Oeste: McLee, 2001. p. 71-83.

MOSCOVICI, Serge. Representações sociais: investigações em psicologia social. Petrópolis: Vozes, 2004.

NÓVOA, António. Os professores na virada do milênio: do excesso dos discursos à pobreza das práticas. Educação e Pesquisa, São Paulo, v. 25, n.1, p. 11-20, jan./jun. 1999.

PENTEADO, Heloísa D. Meio ambiente e formação de professores. 4. ed. São Paulo, Cortez: 2001.

PATO BRANCO. Projeto Político Pedagógico da Escola Rural Municipal S.D.C. Secretaria Municipal de Educação de Pato Branco. Pato Branco, 176p, 2008.

PATO BRANCO. Projeto Político Pedagógico da Escola Municipal V. I. Secretaria Municipal de Educação de Pato Branco. Pato Branco, 299p, 2011.

REIGOTA, Marcos. Meio ambiente e representações sociais. 7. ed. São Paulo, Cortez: 2007.

SANDER, Lucilene. Representações sociais de professores(as) a respeito de meio ambiente e suas práticas pedagógicas escolares em educação ambiental. 2012. 77 f. Dissertação (Mestrado em Desenvolvimento Regional) Universidade Tecnológica Federal do Paraná, Pato Branco, RS, 2012.

SANTOS, Maria de Fátima de Souza; ALMEIDA Leda Maria de (org.). Diálogos com a teoria das representações sociais. Recife: Ed. Universitária da UFPE, 2005. 
SATO, Leny. A representação social do trabalho penoso. In: SPINK, Mary Jane Paris (Org.). O conhecimento no cotidiano: as representações sociais na perspectiva da psicologia social. São Paulo: Brasiliense, 2004.

SOUSA, Clarilza Prado de; VILLAS BÔAS, Lúcia Pintor Santiso. A teoria das representações sociais e o estudo do trabalho docente: os desafios de uma pesquisa em rede. Revista Diálogo Educacional, Curitiba, v. 11, n. 33, p. 271-286, maio/ago. 2011.

TREVISOL, Joviles Vitório. Os professores e a educação ambiental: um estudo de representações sociais de docentes das séries iniciais do Ensino Fundamental. In: II ENCONTRO DA ASSOCIAÇÃO NACIONAL DE PÓS-GRADUAÇÃO E PESQUISA EM AMBIENTE E SOCIEDADE (ANPPAS), 2., 26 a 29 de maio de 2004, Indaiatuba. Disponível em: <http:/ /www.anppas.org.br/encontro_anual/ encontro2/GT/GT10/joviles_trevisol.pdf> Acesso em: 18 set. 2012.

TRISTÃO, Martha. A educação ambiental na formação de professores: rede de saberes. 2 ed. São Paulo: Annablume; Vitória: Facitec, 2008.

VELLOSO, Christiane Santos. Educação ambiental na rede pública do município do Rio de Janeiro: concepções, problemas e desafios. $191 \mathrm{f}$. Dissertação (Mestrado em Educação) - Universidade Federal do Rio de Janeiro, Rio de Janeiro, 2006. 


\title{
Environmental education and social representations of the municipal teachers
}

\begin{abstract}
This paper presents the results of a research that aimed to identify and analyze the social representations of environmental education of teachers of the initial years of the elementary schools of the city of Pato Branco, Paraná. This research involved six teachers of an urban school and six teachers of a rural school. Three instruments of collecting data were used: interview, hierarchization of the evocations and analysis of documents. The collected data were analyzed in accordance to the procedures of content analysis. Based on the collected data, it is concluded that the social representations of the environmental education revolves around the awareness to respect and preserve the environment.
\end{abstract}

Keywords: environmental education, social representations, elementary school

Recebido: 11/12/2012

Aprovado: 27/12/2012 